\title{
A Teoria dos Campos de Bourdieu e a Educação em Ciências: Possíveis Articulações e Apropriações
}

\section{The Bourdieu's Field Theory and Science Education: Possible Articulations and Appropriations}

\author{
Luciana Massi, (D) Gabriela Agostini, ${ }^{\text {(D) }}$ Matheus Monteiro Nascimento
}

Palavras-chave Resumo Visando contribuir para o entendimento da pesquisa em

Sociologia da Educação em Ciências a partir da sociologia da ciência, o objetivo Ciência; deste artigo foi explorar e elucidar a teoria dos campos, formulada Campo Bourdiano; por Pierre Bourdieu, nos objetos de estudo dessa área. Este trabalho Educação em teórico foi estruturado em três momentos, articulados ao longo de

Ciências. todo o texto: uma síntese das leis gerais e invariantes dos campos; a elaboração de uma analogia entre o conceito de campo bourdiano e o campo para a Física; uma discussão da apropriação da teoria dos campos em pesquisas da Educação em Ciências que a mobilizam. Discutiu-se o campo como espaço social, os habitus dos agentes, as posições no campo, as disputas e os interesses, a distribuição de capital específico, os limites, as fronteiras e a autonomia do campo. Defendeuse interpretações desse difícil conceito bourdiano, visando, por exemplo, delimitar o campo e seus agentes, por meio da apropriação em pesquisas da área. Assim, avançou-se no entendimento teórico em diálogo com a área, explicitando as articulações possíveis e as efetivadas entre a Educação em Ciências e a Sociologia da Ciência bourdiana. 
Keywords Abstract Based on contributions from the sociology of science Sociology of in the field of Science Education, this article aims to explore and

Science; elucidate the concept of fields, formulated by Pierre Bourdieu, in the Bordieuan field; objects of study of this area. This theoretical study is structured in Science Education. three parts, which are articulated throughout the text: a synthesis of the general and invariable principles of fields; an elaboration of an analogy between the different field theories (sociology and physics); a discussion about the appropriation of field theories in research studies on Science Education that use them. We discuss the field as a social space, the agents' habitus, the positions in the field, disputes and interests, distribution of the specific capital, limits, boundaries, and the field autonomy. An interpretation of this complex Bourdieusian concept was defended, in a way to determine the limits of the field and their agents, based on how research has appropriated it. Therefore, a theoretical framework was advanced, coming up with the possible and effective articulations between Science Education and Bourdieu' Sociology of Science.

\section{Introdução}

A pesquisa em Educação em Ciências representa um amálgama entre diversas áreas das ciências humanas e exatas. Nessa junção, contribuições de teorias psicológicas e pedagógicas se mostram fundamentais para o entendimento sobre os processos de ensino e aprendizagem em ciências. Esse objeto inicial e central vem sendo ampliado significativamente por meio de contribuições fundamentais da história e filosofia da ciência, das ciências da linguagem e de teorias socioculturais. Apesar disso, a sociologia ainda parece ser pouco explorada quanto à sua contribuição direta para questões educacionais, ao mesmo tempo que as contribuições de alguns sociólogos da ciência vêm sendo investigadas na área, como também observou Valadão (2016). Neste artigo, nos propomos a explorar o potencial do conceito de campo, formulado por Pierre Bourdieu e fulcral em sua sociologia da ciência, para ampliar nossas percepções sobre alguns objetos da nossa área.

O conceito vem sendo investigado por alguns autores, de modo bastante criativo e diverso, sendo possível constatar a preocupação com a escola, os espaços não formais e a ciência como um campo (Feres, 2010; Genovese, 2013; Watanabe et al., 2013). O conceito de campo foi elaborado por Bourdieu como um instrumento de pensamento capaz de indicar uma direção à pesquisa e podendo ser aplicado em diferentes domínios. A ideia de campo surge como uma alternativa à visão simplista e ilusória de uma interpretação interna e uma explicação externa, contra o reducionismo que relaciona diretamente uma forma cultural com uma forma social, Bourdieu (1989a) prezava pelo modo de pensamento relacional, tão caro à sua teoria. Além disso, o conceito tem o poder de colocar a ciência a serviço do progresso da ciência e conduzir tomadas de posição prescritivas (Bourdieu, 2004a). 
Mergulhado na particularidade de diversos casos e pautado pela primazia da empiria, o sociólogo construiu o conceito de campo enquanto o aplicava em diferentes domínios: na alta costura (Bourdieu, 2002a), na arte (Bourdieu, 1996), na ciência (Bourdieu, 1983a, 2004a, 2004b), na economia (Bourdieu, 2005), na política (Bourdieu, 1989b), na religião (Bourdieu, 2007a), no esporte (Bourdieu, 2004c), no direito (Bourdieu, 1989c), na linguagem (Bourdieu, 2008), no espaço intelectual (Bourdieu, 2004d), universitário (Bourdieu, 2017) entre outros.

Sua teoria dos campos foi construída "de generalização em generalização", a cada estudo empírico de universos distintos que revelavam tanto propriedades específicas quanto a recorrência de propriedades comuns e invariantes, que atuavam como mecanismos universais ou leis gerais dos campos (Bourdieu, 1989a, p. 69). De modo coerente com sua teoria sociológica geral, relacional e dialética, o conceito de campo depende e se enriquece de outros conceitos centrais na sociologia bourdiana como habitus, capital, estratégia, estrutura etc. Todos esses elementos contribuem para a dificuldade de compreensão e mobilização do conceito, destacada explicitamente por Bourdieu (2013), Lahire (2017) e Montagner e Montagner (2010). Para Grenfell (2018), a adoção do conceito de campo deveria estar presente em toda pesquisa que se orienta pelas ideias de Bourdieu, evidenciando uma aplicação mais aprofundada da teoria bourdiana e representando um nível superior de entendimento dessa teoria em comparação com a adoção de conceitos isolados, como habitus e capital. Portanto, este conceito com tantas potencialidades para a sociologia da ciência, que vem sendo mobilizado para estudar objetos importantes para a área de Educação em Ciências, exige maior clareza e aprofundamento que não encontramos facilmente na literatura.

Diante disso, neste artigo sistematizamos os resultados de uma leitura detalhada das obras do autor sobre campo, bem como de um conjunto de trabalhos da área de Educação em Ciências (Valadão, 2016) que o mobilizaram, com o intuito de contribuir para o entendimento e a divulgação do conceito na área, explicitando as articulações possíveis e as efetivadas. Objetivamos, assim, tornar o conceito de campo mais claro teoricamente, ilustrando-o por meio de suas apropriações pela área da Educação em Ciências e de uma analogia com o conceito de campo presente na Física. Assim, nosso objetivo principal é aprofundar o entendimento deste difícil conceito, ilustrando-o por meio de apropriações pelas pesquisas em Educação em Ciências e de uma analogia. Logo, trata-se de um estudo teórico e conceitual que não pretendeu revisar completamente a literatura, nem aprofundar as discussões sobre analogia, tampouco esgotar as possibilidades de apropriação do conceito de campo pela área. Destacamos que as similaridades apresentadas entre o mundo social e o físico serão, em alguns momentos, de mera aparência ou literais; em outros casos, contudo, serão próprias analogias (Genter, 1983). Compreendemos a relevância do reconhecimento dessas diferenças (Mozzer \& Justi, 2013), contudo, no presente trabalho vamos sinteticamente utilizar analogia como substantivo que denota semelhanças e conformidades; e não no sentido estrito do conceito amplamente discutido na área da Educação em Ciências. 
Para produzir essa análise teórica, durante um ano nos debruçamos sobre a leitura atenta de diversas obras de Bourdieu sobre o conceito geral do campo (1983c, 1989a), sobre outros campos (1983b, 1989b, 1989c, 1996, 2002a, 2004c, 2004d, 2005, 2007a, 2008) e sobre o campo científico (1983a, 2004a, 2004b, 2017), produzindo sínteses sobre as leis gerais e invariáveis e as propriedades específicas dos campos; um primeiro esboço de uma comparação entre o conceito de campo para Bourdieu e para a Física, que serviram de base para a analogia aqui apresentada.

Em seguida, retomamos a revisão bibliográfica produzida por Valadão (2016) sobre a apropriação do referencial bourdiano nas pesquisas em Educação em Ciências. A autora fez uma revisão sistemática das principais publicações da área: nos anais do Encontro Nacional de Pesquisa em Educação em Ciências (ENPEC), da $1^{\text {a }}$ à $9^{a}$ edição; em periódicos avaliados como A1/A2 no Ensino (Revista Brasileira de Ensino de Física, Revista Brasileira de Pesquisa em Educação em Ciências, Revista Ciência \& Educação, Revista Ensaio Pesquisa em Educação em Ciências e Revista Investigações em Ensino de Ciências); em teses e dissertações disponíveis no Centro de Documentação em Ensino de Ciências e no Banco de Teses da CAPES. Do total de 160 trabalhos analisados por Valadão (2016) selecionamos 16 que mobilizavam o conceito de campo (Braga, 2004; Conceição, 2012; Condenanza \& Cordero, 2011; Dorvillé, 2010; Feres, 2010; Feres \& Nardi, 2007; Freitas, 2008; Freitas, Oliveira \& Carvalho, 2005; Freire \& Fernandez, 2015; Genovese, 2013; Martins et al., 2005; Pereira, 1999; Perrelli, 1996; Perrelli \& Gianotto, 2005; Ribeiro, 2008; Watanabe et al., 2013). A partir dessas referências, procuramos, quando possível, trocar textos de congresso por teses e dissertações dos mesmos autores, buscando abordagens mais amplas do conceito de campo, assim incluímos na análise as teses de Condenanza (2012), Genovese (2008) e Watanabe (2015), totalizando 19 textos. Diante da leitura completa desses materiais e considerando o objeto de estudo dos autores, analisamos como o conceito de campo estava sendo mobilizado, quais propriedades deste conceito e que outros conceitos bourdianos eram articulados, qual era o panorama teórico em que Bourdieu estava inserido nessas pesquisas e quais os avanços e limites desse esforço de mobilização teórica. Reforçamos que alguns trabalhos da área, pautados na teoria bourdiana, não foram incluídos em nossa análise, sobretudo aqueles publicados depois de 2015, visto que nos baseamos apenas na revisão de Valadão (2016). Nesse sentido, não pretendemos fazer generalizações, mas apontar um panorama, situado temporalmente, da apropriação do conceito de campo nas pesquisas da Educação em Ciências.

De modo geral e descritivo, destacamos inicialmente a prevalência de dez teses e dissertações (Braga, 2004; Conceição, 2012; Condenanza, 2012; Dorvillé, 2010; Feres, 2010; Freitas, 2008; Genovese, 2008; Perelli, 1996; Ribeiro, 2008; Watanabe, 2015), um único artigo (Freire \& Fernandez, 2015) e oito trabalhos de congresso (Condenanza \& Cordero, 2011; Feres \& Nardi, 2007; Freitas et al., 2005; Genovese, 2013; Martins et al., 2005; Pereira, 1999; Perelli \& Gianotto, 2005; Watanabe et al., 2013), sendo que cinco desses trabalhos (Condenanza \& Cordero, 2011; Feres \& Nardi, 2007; Genovese, 
2013; Perelli \& Gianotto, 2005; Watanabe et al., 2013) tinham relação direta com as teses e dissertações dos mesmos autores. Tratam-se de pesquisas pautadas, exclusivamente, em métodos de coleta de dados de natureza qualitativa, com destaque para a técnica de entrevista e análise dos discursos dos sujeitos de pesquisa. Nesse sentido, alguns trabalhos adotam a Análise de Conteúdo, de Laurence Bardin, como técnica de seleção, organização e análise de dados. Percebemos também, na maioria dos trabalhos, que o referencial teórico bourdiano vinha acompanhado de outros autores, como Paulo Freire, Thomas Kuhn, Ives Chevallard, entre outros. Freitas (2008), por exemplo, indicou que Bourdieu não possibilita análises da dimensão epistemológica da pesquisa, por isso o associou a Paulo Freire. Por fim, embora trate-se de um grupo pequeno de 23 autores, destacamos a ausência de citações entre esse grupo de autores, ou seja, percebemos que os autores da área de Educação em Ciências não citavam seus colegas que também adotaram o conceito bourdiano de campo e, eventualmente, nem citavam suas próprias pesquisas publicadas em outro contexto.

$\mathrm{O}$ artigo está estruturado de modo que, ao longo de todo o texto, apresentamos o conceito de campo a partir de Bourdieu, aprofundamos esse conceito por meio de uma analogia com a Física e discutimos como o conceito de campo foi apropriado por pesquisas da Educação em Ciências.

\section{Campo como um espaço social}

Bourdieu constrói o conceito de campo em associação direta com a noção física de espaço. Para o autor, os campos seriam como microcosmos dentro do macrocosmo social. Ou seja, a referência ao conceito de campo está precisamente relacionada com a noção de espaço, mais precisamente de espaço social. O filósofo Nikolaus Fogle (2011) demarca bem a relação entre campo e espaço na obra bourdiana. Nas palavras do autor:

A concepção de campo religioso que Bourdieu constrói em resposta a Weber exemplifica o que ele chama de campo de produção cultural: um campo cujo conteúdo é restrito a um tipo particular de atividade cultural, como literatura, pintura, jornalismo ou direito, e que é entendido como um subespaço do espaço social mais abrangente. (Fogle, 2011, p. 4, tradução nossa).

Assim, quando Bourdieu está se referindoaocampoliterário, artístico, universitário ou religioso, ele está tratando de subespaços que estão todos envolvidos por um grande espaço social. Nestes subespaços do espaço social, que são genericamente chamados de campos, os agentes (indivíduos, instituições, etc.) estão posicionados como se fossem partículas carregadas localizadas em algum ponto do espaço físico. Estes agentes, assim como as partículas, interagem mutuamente neste espaço e as consequências destas interações estão intimamente relacionadas com propriedades intrínsecas destes agentes.

Mas de qual espaço estamos falando? A noção física moderna de espaço é resultado de um longo e contínuo processo de abstração, que tem origem no ser humano primitivo (Jammer, 1993). Afastando-se de descrições puramente geométricas, o espaço 
adquire com Newton o status de realidade absoluta, na qual os fenômenos físicos seriam descritos matematicamente (dos Reis \& Reis, 2016; Porto \& Porto, 2008). O espaço seria, portanto, apenas o território passivo dos acontecimentos, sem qualquer influência ou interação com os fenômenos físicos. Com o tempo, a proposição de Newton sobre o espaço absoluto foi gradativamente se consolidando entre aqueles que pensavam o mundo físico (Jammer, 1993; Porto \& Porto, 2008). A despeito do sucesso da mecânica newtoniana, suas ideias sobre o absolutismo do espaço não deixaram de ser questionadas por pensadores como Gottfried Leibniz, Leonhard Euler, Ernest Mach e Henri Poincaré (Porto \& Porto, 2008). Somando-se a essas críticas, o problema da incompatibilidade entre a teoria eletromagnética de Maxwell e as leis da mecânica vigentes fizeram emergir uma nova interpretação física do espaço e do tempo, a teoria da relatividade restrita proposta por Einstein (Jammer, 1993). Para sua proposta de relatividade, era preciso ainda considerar as contribuições do matemático Riemann, o qual assumia o espaço como um agente ativo dos acontecimentos físicos (Einstein, 2011). Com Einstein, em resumo, vemos o fim do espaço absoluto e o surgimento da sua conexão com o tempo num continuum de quatro dimensões indissociáveis.

Assim, o espaço social investigado por Bourdieu se ancora nessa noção moderna de espaço físico, na qual as dimensões espaciais estão imbricadas com a dimensão temporal. Bourdieu, nos seus trabalhos, utiliza uma representação plana bidimensional do espaço social. O tempo, apesar de considerado nas análises bourdianas, não é representado, pois está em uma dimensão perpendicular ao espaço social (Fogle, 2011).

A utilização desta noção de campo com um espaço ou subespaço do espaço social aparece nos trabalhos da área da Educação em Ciências analisados. Na tese de Freitas (2008), por exemplo, o conceito de campo é mobilizado para compreensão das relações entre o trabalho do professor universitário e do professor da escola. A autora "procura situar o acadêmico, enquanto professor universitário, como parte integrante de uma estrutura social autônoma que se relaciona com as demais estruturas no 'espaço social"' (Freitas, 2008, p. 15). Esta estrutura social autônoma, para Freitas (2008), situada no interior de um espaço social maior, é exatamente o que entende-se por campo, que no caso específico corresponde ao campo acadêmico ou universitário. Ela conclui reconhecendo as diferenças entre o espaço social ocupado por esses dois agentes e advogando pela criação de espaços "inter-campos" que possibilitem o diálogo e a troca de saberes entre eles. Os dados coletados são oriundos de reuniões entre esses agentes e a análise desses diálogos é feita com base na Análise de Conteúdo. Há o entendimento do campo como um microcosmo e da universidade como micro-organização ou subcampo, em torno de áreas de conhecimento, se relacionando com outros campos de maneira relativamente permeável. Parte dessas ideias estão presentes no trabalho de Freitas, Oliveira e Carvalho (2005), em que fica mais explícita a relação de proximidade e distanciamento no espaço inter-campos (campo escolar e campo científico), pois é apresentada uma configuração entre agentes e campo, por exemplo, mostrando que entre o professor universitário e o da escola pode haver uma aproximação pela experiência docente e um distanciamento 
em relação à pesquisa. Assim, há um destaque para o entendimento do campo como um espaço social que possibilita a análise das distâncias e proximidades entre os agentes de diferentes campos. Os autores reconhecem que Bourdieu, em Razões Práticas, considera a posição do sujeito em relação ao próprio campo, mas pretendem explorar essas posições "inter-campos", há ainda uma aposta na possibilidade de articulação partindo da ideia de que os novatos produzam mudanças no campo (Freitas et al., 2005).

Uma questão central no estudo do conceito de campo trata das leis gerais e invariáveis destes subespaços do espaço social, de forma que não é qualquer área do conhecimento, profissão ou instituição que pode ser considerada um campo autônomo. Dentre os diversos conceitos elaborados por Bourdieu para construir a teoria dos campos, discutimos neste artigo, principalmente o habitus dos agentes, a composição e distribuição de capitais, a estrutura e relação de forças, o nomos, a doxa, a crença e os interesses em disputa, as fronteiras e autonomia do campo e as estratégias do jogo ${ }^{1} . \mathrm{Na}$ próxima seção abordamos esses pontos em diálogo com os trabalhos analisados.

\section{As leis gerais e invariáveis dos campos}

Um campo é um espaço estruturado de posições disputadas por agentes e instituições. Examinando essa definição podemos fazer uma analogia, assim como faz Bourdieu, e pensar o campo como um jogo no qual há uma disputa em comum, um conjunto de regras próprias e limites que precisam ser seguidos, jogadores mais ou menos habilidosos e interessados na competição, parceiros com os quais se joga e outros dos quais se opõem, estilos e maneiras apropriadas para jogar; é preciso haver ainda cartas ou trunfos distribuídos e manipulados entre os jogadores, estratégias a serem utilizadas para ocupar uma ou outra posição, percursos a serem conquistados e movimentos possíveis de serem realizados no espaço do jogo.

Nesse espaço há objetos de disputa e interesses irredutíveis, percebidos apenas por quem é formado ou interessado em entrar nesse campo. Por exemplo, no campo científico o que está em jogo é o poder de impor uma concepção de ciência que limite os problemas, os métodos e as teorias consideradas legítimas; e de estabelecer uma ordem científica (Bourdieu, 1983a). Assim, é de suma importância que se estabeleça como ponto de partida para a descrição de um campo as regras que estão sendo jogadas naquele subespaço social, sob pena de relativizar o conceito a ponto de reduzir o seu poder analítico. Por exemplo, a tese de doutorado de Feres (2010) teve como objetivo investigar a área de ensino de ciências, em específico os programas de pós-graduação, compreendendo sua origem, constituição e institucionalização. Partindo do princípio de que a pós-graduação em ensino de ciências é um campo científico, a autora busca

1 Demais conceitos como posição, disputa, legitimidade, campos específicos (poder, econômico, religioso, científico, escolar entre outros) e homologia, também presentes na teoria dos campos, são apenas citados e não aprofundados, visto que não é nosso objetivo detalhar toda a teoria e o espaço do artigo não permite explicar todos os termos e conceitos apresentados. Para sanar essas eventuais dúvidas sobre os conceitos bourdianos sugerimos a consulta ao Vocabulário Bourdieu organizado por Catani, Nogueira, Hey e Medeiros (2017). 
mobilizar, sob a ótica bourdiana, o habitus próprio desse campo, seu capital intelectual e as estratégias que caracterizam as disputas e os interesses de seus agentes. Feres (2010) apresenta uma minuciosa reconstrução histórica da área (ocupando mais de 100 páginas da tese), no entanto, as discussões sobre as propriedades específicas que justifiquem esse espaço como um campo não têm o mesmo nível de detalhamento. Como se nota ao sintetizar a pós-graduação como um campo, Feres (2010, p. 208) afirma que é:

um campo científico com objeto e objetivos próprios, sendo dominante a contribuição dos programas de pós-graduação para a sua constituição e institucionalização no país; que nesse campo constituído é visível a existência de um habitus com dimensões e características próprias, embora similares a outros campos em que congrega suas relações multidisciplinarmente; e, que também se pode inferir sobre a presença de um capital cultural ou científico que demonstra uma trajetória e tradição constituídas mediante estratégias específicas e delimitadas por uma ambiência que apresenta fatores de influência de natureza vária.

Ou seja, ao invés de mostrar os mecanismos que estruturam as lutas do campo e desvelar sua lógica interna, a autora faz a opção de reproduzir os conceitos bourdianos em uma análise mais descritiva, genérica e menos relacional.

No mesmo sentido, Pereira (1999) desenvolve sua pesquisa sobre o prestígio dos cursos de formação docente a partir da reconstrução do processo histórico de emergência do curso de Ciências Biológicas da UFMG, considerado pelo autor um campo específico. De forma semelhante a Feres (2010), Pereira (1999) apresenta detalhadamente a gênese desse curso, mobilizando alguns conceitos fundamentais como habitus e capital, entretanto, talvez pelo pouco espaço disponível, o autor não investe na articulação e aprofundamento dos conceitos que possibilitem interpretar, e não apenas anunciar, o curso em questão como um campo autônomo e bem estabelecido. Freitas e Fernandez (2015) também entendem o campo como um espaço social com estrutura particular e objetivos específicos, que funciona de forma relativamente autônoma. Elas enunciam a existência de um campo profissional dentro do campo universitário, no qual se insere o subcampo da docência universitária. Afirmam, ainda, que um "campo é tão mais autônomo quanto mais se consome os produtos desse campo, indicando a necessidade de um polo produtor e outro consumidor dentro do próprio campo" (Freitas \& Fernandes, 2015, p. 260). Nesse sentido, afirmam que a docência é consumida pelos graduandos. Na questão de pesquisa há menção ao "campo educacional", mas não fica clara a relação deste, que aparece apenas nas seções introdutórias do artigo, com os outros campos enunciados, como é feito em relação ao subcampo da docência universitária.

Percebemos que essas três pesquisas têm em comum o fato de considerarem a existência do campo como um dado a priori, ou seja, sem explicitar a referência e identificação das leis gerais e das propriedades específicas de campo definidas por Bourdieu, partem do princípio que estudam um campo. Entendemos que a delimitação entre o que é ou não um campo não é clara no autor e percebemos que alguns espaços 
funcionam como campos ou subcampos dependendo das relações que estão sendo estudadas. Assim, ora a alta costura é um campo (Bourdieu, 2002a) ora ela é um subcampo do campo da produção intelectual (Bourdieu, 1968). Entendemos que essas variações não representam inconsistências, mas abrem a possibilidade de diversos enfoques relacionais no estudo dos campos. Desse modo, ao situar um campo ou subcampo em relação aos campos adjacentes, Freitas e Fernandez (2015) por exemplo evidenciam esse esforço de delimitação do campo.

No entanto, defendemos que há uma dimensão fundamental do conceito que nos parece ausente em algumas pesquisas que definem o campo apenas como um espaço estruturado de posições, ou seja, desconsideram que essas posições só são estruturadas em função da posse de determinado volume de capital específico. Assim, o que está em disputa não são as posições, mas o capital, que exige a identificação de um capital específico claramente almejado por todos os agentes do campo. Isso também é feito por Freitas e Fernandes (2015) ao situar o capital da docência universitária. Porém, o conceito de capital exige a identificação de determinado reconhecimento e rentabilidade, ou seja, só é capital se puder ser trocado por benefícios ou lucros vantajosos. O conjunto dos trabalhos da área discutidos neste artigo indicam campos e capitais específicos, porém não explicitam essa dimensão conceitual do capital. Além disso, entendendo que a noção de campo surge para superar a falsa dicotomia entre internalismo e externalismo e reconhecendo que a existência de fronteiras e autonomia é o que define a existência do campo, percebemos que o capital específico de um campo deve ser minimamente reconhecido fora das fronteiras do campo. Isso fica claro quando Bourdieu (1983a) indica que a disputa no campo científico é pela verdade científica e que este capital e seus detentores são reconhecidos publicamente fora dos limites internos do campo. Com essa interpretação e inserção do "campo da docência superior" no "campo universitário" temos dificuldade em reconhecer a legitimidade e o valor do capital da docência universitário, indicado por Freitas e Fernandez (2015) como a capacidade de dar boas aulas e a experiência didática, uma vez que isso não é reconhecido internamente na universidade e muito menos externamente. Assim, embora essa constatação seja extremamente desfavorável para todos nós envolvidos na Educação em Ciências, nos parece que o conceito de campo não contribui para compreender essas disputas que, provavelmente, não remetem a um campo.

Além disso, é importante destacar que, segundo nossa interpretação pautada nas obras de Bourdieu (2007b, 2008), todos estamos inseridos no campo linguístico e no campo das classes sociais. Assim, sofremos a influência dessa disputa por capitais e posições mais legítimas em que há um claro reconhecimento e rentabilidade de capitais considerados mais legítimos nesses campos. Portanto, entendemos que é necessário fazer um esforço para diferenciar disputas próprias de um campo e disputas gerais de classes sociais, por exemplo, às quais sempre estamos sujeitos. Confirmando este nosso entendimento, Lahire (2002) afirma que alguns espaços sociais, como a família, não são campos, uma vez que as posições ocupadas não podem ser trocadas e, podemos 
acrescentar de acordo com nossa argumentação, que o que está em disputa não é rentável nem reconhecido fora dos limites internos da família.

Avançando para os elementos internos e constituintes dos subespaços sociais, para que um campo funcione é preciso que haja pessoas (agentes) e instituições dispostas a disputar esse jogo. Os agentes são dotados de um habitus próprio que implica em conhecer e reconhecer as leis desse campo (Bourdieu, 1989a). Sendo o produto da interiorização da estrutura do jogo, esse sistema de esquema de pensamentos, percepções e apreciações, que é o habitus, determina as habilidades dos jogadores, a forma como poderão jogar e as posições que poderão ocupar. Na Física clássica, a interação entre partículas que não estão em contato foi um fato muito estranho aos físicos do século XVIII. Com isso, para explicar as forças de ação a distância foi desenvolvido um recurso matemático que se denominou de campo (Griffiths, 2005; Jackson, 2007; Jammer, 1993; Nussenzveig, 2015). Este ente matemático, assim, estaria espalhado pelo espaço físico e justificaria a interação das partículas mesmo a grandes distâncias. Com isso, dizemos que a interação entre partículas carregadas e posicionadas no espaço físico é sempre mediada pelo campo. No caso da eletrostática, por exemplo, dizemos que cada partícula individualmente produz no seu entorno um campo elétrico que é mais intenso quanto maior for a carga do corpo e vai diminuindo conforme nos afastamos da partícula. Em outras palavras, cada partícula carregada produz o próprio campo no qual está inserida. A utilização do campo para analisar interações entre corpos a distância também se faz presente em outros ramos da Física, como no magnetismo e na gravitação. Considerando a natureza relacional da teoria bourdiana dos campos (Klüger, 2018), não faz sentido analisarmos a participação dos agentes isoladamente no espaço social. É fundamental entendermos de que maneira um agente se posiciona neste espaço sempre em relação à posição dos outros agentes que fazem parte do espaço social.

A dissertação de mestrado de Conceição (2012) teve como objetivo avaliar as políticas públicas voltadas à Iniciação Científica (IC) em uma universidade estadual, pautada na noção bourdiana de campo científico. O autor apresenta uma reconstituição histórica da IC no Brasil identificando os principais agentes, as instituições e os contextos que possibilitaram o surgimento da pesquisa científica brasileira. Em seguida, avalia a implementação de programas de IC Júnior em uma universidade, analisando as competências, o tempo, os recursos e as estratégias que a instituição demanda aos participantes dos programas, ou seja, investigando os aspectos constitutivos do habitus científico demandado pelo campo universitário. No entanto, pauta-se no discurso dos sujeitos para analisar o habitus, considerando o aluno de IC como um agente do campo Conceição (2012) entende a constituição do habitus de modo imediato e não como uma estrutura estruturante e formadora de esquemas de pensamento. Para o autor, a convivência por um tempo em laboratórios de pesquisa é suficiente para formar um habitus adequado ao campo no aluno de ensino médio, capaz de constituí-lo como um agente que disputará nesse campo. Análise semelhante ocorre com Perelli e Gianotto (2005), ao investigar as percepções de professores universitários na escolha de alunos 
de IC, as autoras assumem que a vivência em laboratório e em grupos de pesquisa, por um breve período de tempo, é capaz de formar nos estudantes um habitus científico que reflete a ciência normal. Sendo os estudantes de IC considerados como agentes do campo, para as autoras, o jogo da ciência começa a ser jogado por eles bem antes de entrarem na universidade ao desenvolver competências, como autonomia e tomada de decisões, que são exigidas pelo campo científico.

Na sua tese de doutorado, Dorvillé(2010) analisa as tensões e conflitos que emergem do deslocamento de um mesmo agente entre campos, a saber, do campo religioso para o campo científico. Foram estudados os processos identitários de estudantes evangélicos de um curso de Biologia e sua relação com os conteúdos acadêmicos (Dorvillé, 2010). $\mathrm{O}$ autor assume como fundamental que o ensino de ciências promova alterações nas visões de mundo dos estudantes a partir da promoção de situações dissonantes com o habitus original desses alunos. Em nossa interpretação, Dorvillé (2010) extrapola as noções bourdianas ao considerar os estudantes evangélicos como agentes do campo religioso, assim como Conceição (2012) ao considerar estudantes do ensino médio como agentes do campo científico. Freitas e Fernandez (2015) também entendem os alunos como componentes da configuração do campo e não como "seres submissos", em outro momento afirmam que eles são agentes do campo da docência universitária, pois eles atribuiriam capital para os docentes conhecidos pela qualidade de suas aulas. Não estamos afirmando que não o sejam, porém, seria necessário um maior investimento teórico e empírico por parte dos autores para sustentar estas teses. $\mathrm{Na}$ definição de propriedades do campo, Bourdieu (1983c) claramente indica que os agentes no campo são apenas aqueles que detém o habitus específico e estão em condições de disputar o capital específico do campo, além disso define dois tipos de estratégias empregadas por esses agentes em relação ao capital específico: conservação ou manutenção. Lahire (2002) afirma que nem todos os envolvidos ou próximos ao campo são agentes, exemplificando esse entendimento com a situação do gandula em uma disputa de tênis que não pertence ao campo esportivo. Assim, subentendemos que só é agente quem participa efetivamente da disputa, não quem apenas assiste. Logo, temos dificuldade em imaginar que o fato de frequentar uma igreja ou uma universidade habilite esses agentes a disputar o capital específico desses campos.

Tomando cuidado para não posicionar a priori indivíduos em campos específicos e reconhecendo nosso pertencimento ao campo linguístico, Martins et al. (2005) analisam o discurso de professores de ciências em oficinas para formação docente. As autoras fazem uma análise do habitus linguístico do lugar de origem de onde o discurso é originado, identificando uma hibridização entre discursos dos campos científico e pedagógico. Em vez de assumir que o habitus de um professor é o habitus próprio do campo científico e o considerar um agente participante deste campo, as autoras mostram que o discurso deste indivíduo se aproxima de um habitus linguístico que é próprio do campo científico, muitas vezes incorporado no ambiente acadêmico universitário. Reiteramos que todos pertencemos ao campo linguístico, pois ele não se refere ao campo 
da produção linguística que, provavelmente, se situa no campo acadêmico, científico ou universitário, mas remete a um campo de uso da língua, como explicado por Bourdieu (2008).

A força de um agente e sua posição no campo dependem do seu patrimônio de capitais. Os capitais podem ser entendidos como os trunfos do jogo, os poderes que são distribuídos, trocados e acumulados. Em cada campo há um capital específico acumulado ao longo das lutas anteriores e distribuído de modo desigual entre os agentes e as instituições desse campo. Essa distribuição configura a estrutura, isto é, estabelece um estado de relações de força que se exerce sobre todos aqueles engajados no campo. Isso significa que o "peso associado a um agente depende de todos os outros pontos e das relações entre todos os pontos, isto é, de todo o espaço compreendido como uma constelação relacional" (Bourdieu 2005, p. 24). Um olhar para a Física clássica nos ajuda a visualizar estas definições. Uma interpretação básica na eletrostática indica que a carga elétrica de um corpo eletrizado é dependente do número de elétrons em excesso ou em falta neste corpo. Quer dizer, quanto mais ou menos elétrons em relação ao estado neutro um corpo tiver, maior será o módulo da sua carga elétrica e, consequentemente, maior será a interação com os outros agentes presentes no espaço físico. Para Bourdieu (1983c), dentro do espaço social os agentes se distribuem hierarquicamente a partir de suas propriedades sociais, com agrupamentos formados a partir de similaridades entre estas propriedades. Ou seja, entre um grupo de agentes, quanto mais comum for determinada propriedade social, maior a chance destes agentes estarem posicionados proximamente no espaço social. Por exemplo, pessoas com elevado capital cultural tendem a se agrupar no espaço social, pois compartilham uma série de gostos e disposições que não são próprias dos agentes de baixo capital cultural, que por outro lado, também estarão mais ou menos agrupados no espaço social, mas pelo compartilhamento de outras propriedades (Bourdieu, 1983c). Assim, quanto mais frequente entre os agentes do espaço for a propriedade de um agente específico, maior a chance destes agentes estarem agrupados de forma coesa. Portanto, a recorrência da propriedade social de um agente dentro do grupo aumenta a chance de agrupamento, ou seja, esta frequência tem a característica de aproximar os agentes, que é uma característica própria da força elétrica coulombiana².

\section{Algumas propriedades específicas dos campos}

Os interesses do campo ditam as regras do jogo e em cada campo busca-se impor um ponto de vista legítimo sobre o campo, uma lei fundamental, um princípio de visão e divisão, isto é, um nomos que define um campo artístico (ou outro) enquanto tal, como o lugar da arte enquanto arte, que determina os artistas verdadeiros (Bourdieu, 1996).

\footnotetext{
2 No caso da Física, a atração entre as partículas ocorre quando os sinais de suas cargas são opostos e a repulsão quando os sinais das cargas são iguais. Assim como enfatizado por Bourdieu (Klüger, 2018), ressaltamos os casos de atração entre os agentes pela proximidade com os fundamentos das Análises de Correspondências.
} 
O nomos confere o direito de entrada ao campo, define os limites dos grupos formados e as condições de participação, só entra quem estiver dotado do ponto de vista do campo, isto é, quem souber as regras e estiver disposto a jogá-las.

Freitas (2008, p. 28) confere destaque a essa propriedade para analisar o campo, pois "nos remete à questão da dóxica assumida pelos sujeitos/agentes", entendida pela autora como a manutenção de "um projeto de sociedade que está dado" em que "qualquer processo de transformação é assumido como prejudicial, uma vez que em todo o processo de transformação há uma perda de capital já que questiona a lógica desse sistema”. A autora entende que nesse sistema qualquer tentativa de mudança faz com que o agente se sinta marginalizado. Esse entendimento de doxa e interesse desconsidera que o campo se define, justamente, pela disputa de posições e capitais que revelam a doxa, por exemplo na disputa entre o velho e o novo que ocorre no campo da alta costura (Bourdieu, 2002a). Freitas e Fernandez (2015) também destacam essa disputa no campo da docência universitária apontando para o capital da experiência docente como algo que participa da disputa de poder no campo e que aparece como o não-fornecimento de apoio a um colega iniciante; os novatos no campo acumulariam capital cultural e simbólico até conseguirem questionar as regras do jogo em uma relação dominante-dominado que os mais experientes exercem sobre os mais novos; "a obtenção de prestígio junto aos alunos é um meio de aumentar o capital simbólico e a relação de poder junto aos demais agentes do campo" [...] "se ele 'fraquejar' na maneira de transmitir o conhecimento pode ser considerado um docente menos eficiente e ter uma posição inferior no campo" (Freitas \& Fernandez, 2015, pp. 266-267). Na conclusão as autoras reiteram as "características próprias, tensões e dificuldades do microcampo do trabalho docente no Ensino Superior em início de carreira" (Freitas \& Fernandez, 2015, p. 270), indicando relações de superioridade dos docentes novatos em relação aos alunos e de dominação dos docentes experientes em relação aos novatos.

Esse conjunto de discussões apresentadas até aqui nos parecem evidenciar a forte relação que um agente estabelece com seu campo, levando-o a desenvolver, por meio de um processo longo e recorrente, um habitus próprio além do seu habitus original do campo das classes sociais. Portanto nos causa estranhamento a ideia, apresentada por alguns autores (Conceição, 2012; Freitas, 2008; Perrelli, 1996; Perelli \& Gianotto, 2005), de que os agentes podem estar em vários campos ao mesmo tempo, que seria possível ao agente reconhecer sua posição no campo e, ao tomar consciência dessa posição, mudar seu habitus ou sua estratégia, quase como se os agentes tivessem a capacidade de transitar facilmente entre campos, como uma ideia de "campo flex". Perrelli (1996) compara o habitus à noção de obstáculo epistemológico que, embora aponte coerentemente para o caráter de aparente inatismo e espontaneidade, aposta na possibilidade de superação ou mudança do habitus. Outra comparação da autora é feita ao apresentar o campo como zonas do perfil conceitual, ao perceber a posição inferior dos escritores no campo da indústria cultural, devido ao seu baixo capital cultural e econômico, e sugerir que os autores invistam em seu capital cultural visando subverter essas posições. É importante 
destacar que na única obra em que analisa processos de transformação, envolvendo a mudança da sociedade tribal argelina para o modo de produção capitalista, Bourdieu (1979) explicita muito mais a histerese do habitus, ou seja, a tendência do indivíduo em manter seu habitus original ainda que ele esteja inadequado para a nova situação, do que a mudança.

Assim como na pesquisa de Freitas e Fernandez (2015), outros autores se dedicam a definir um capital específico para o campo estudando e discutindo sobre suas implicações nas posições dos agentes (Condenanza, 2012; Perrelli \& Gianotto, 2005; Ribeiro, 2008; Genovese, 2008). Entendendo a educação ambiental como um campo, Condenanza (2012) em sua tese de doutorado, analisa a disputa por um capital simbólico específico desse campo, relacionado com a possibilidade de impor, pela ação e teoria, diversos projetos políticos refletindo as finalidades da educação ambiental. Perelli e Gianotto (2005) ao investigar os alunos de IC também assumem a existência de capitais específicos do campo científico, dado pela titulação e pelas publicações em parceria com o orientador da pesquisa e pelo interesse na aquisição de autoridade. Para Conceição (2012), os alunos de IC acumulariam capital simbólico e cultural, enquanto agentes do campo científico, que os ajudariam a ingressar no ensino superior, por meio do vestibular, ilustrando o caráter de permuta do capital, ainda que de modo bastante utilitarista. Ribeiro (2008), que em sua tese de doutorado investigou os embates políticos e epistemológicos subjacentes à implementação de um curso de licenciatura em química noturno, captou as negociações simbólicas e a prevalência de interesses de grupos hegemônicos associados à criação e organização desse curso.

Um dos estudos mais aprofundados sobre o campo, que constrói o campo da escola em relação ao campo escolar, definindo seus capitais específicos é a pesquisa de doutorado de Genovese (2008). O campo da escola refere-se à escola específica que o autor estudou e o campo escolar é mais amplo, associado ao sistema escolar. Ele tem como objeto o conhecimento e reconhecimento de uma professora no campo escolar, que constituem o que ele denomina de homo magister. Para configurar esse campo, analisa o campo de poder da cidade e a posição de uma escola em relação às outras da cidade, definindo-a como dominante dentro de um campo escolar. O campo escolar, segundo o autor, recebeu breves menções de Bourdieu (em Coisas Ditas e Razões Práticas) e é defendido por ele com base nos seguintes argumentos: 1) a existência de um jogo entre as escolas e sua capacidade de resistir às mudanças; 2) a escola já construiu de modo autônomo disciplinas e materiais escolares (ciências e geografia); 3) a escola e o ensino têm uma história própria. Como metodologia de análise o autor indica a seguinte sequência: configurar o campo do poder, identificar a estrutura das relações objetivas entre as escolas e identificar os sistemas de disposições e habitus dos agentes. Ele define o capital docente como a soma do capital cultural escolar e o capital social, sendo o primeiro disponível nas três formas (hierarquia das matérias, sentido do jogo escolar e posse de recursos) e o segundo como a capacidade de manter relações interpessoais de conhecimento e reconhecimento. O campo escolar "é um campo de forças relativamente 
autônomo dotado de estrutura estruturante e estruturada, pela distribuição e hierarquização das escolas e dos professores" (Genovese, 2008, p. 171), rompendo com visões internalistas e externalistas. Em um trabalho do ENPEC, Genovese (2013), analisa a interação entre o campo escolar e universitário, o autor defende esse termo, ao invés do termo relação universidade-escola, considerando que esses espaços são "estruturados e estruturantes" indicando para a concorrência e relações hierarquizadas entre os agentes. Ele considera que o ensino de ciências é um subcampo acadêmico e que existem outros campos como o campo científico educacional, campo científico educacional do ensino de ciências e o campo científico das ciências básicas. $\mathrm{O}$ autor distingue entre o campo escolar e o campo da escola, situando também o habitus do homo magister e o capital docente. Nesse contexto, o capital social "é expresso pela capacidade do professor em estabelecer, manter e mobilizar as relações interpessoais" e o estudo sobre os grupos de pesquisa entre universidade e escola constituem um esforço de "interseccionar os campos escolar e universitário" (Genovese, 2013, p. 3). Assim como na tese, o autor mobiliza os capitais específicos do campo escolar: o capital cultural escolar e o capital social. $\mathrm{O}$ autor identifica vários obstáculos, como o campo da escola que acumula capital cultural escolar e o professor supervisor que possui um habitus que agrega capital social. Como discutido anteriormente, apesar do detalhamento metodológico e empírico, bem como da apropriação aprofundada da teoria bourdiana, não conseguimos identificar a legitimidade e rentabilidade dos capitais docentes que este autor define.

O campo possui limites e fronteiras que também são objetos de conflito e disputados no jogo, pois defender as fronteiras é defender a ordem estabelecida no campo, seu nomos e regras (Bourdieu, 1996, 2005). As fronteiras determinam a autonomia de um campo, que é sempre parcial, jamais se atinge a subordinação total à demanda externa, tampouco a independência absoluta às exigências do mercado (Bourdieu, 1996). O processo de autonomização é gradual, concomitante à constituição histórica do campo e proporcional ao capital simbólico acumulado no decorrer do tempo. Um maior grau de autonomia supõe a delimitação mais clara das fronteiras, certa independência dos poderes externos políticos ou econômicos, a constituição de interesses autênticos subordinados à lógica do campo, a capacidade de definir por si próprio seus princípios de legitimidade, a imposição de seu nomos e o reforço de suas leis, o poder de fazer alusão à história interna do campo, o aprimoramento na codificação das regras, a elevação do direito de entrada e uma maior reflexividade como uma espécie de crítica sobre si mesmo (Bourdieu, 1989b, 1996). Relacionando com o conceito de campo elétrico, este se torna menos intenso na medida em que nos afastamos do corpo, como vimos anteriormente. Quando a distância tende ao infinito, a intensidade do campo elétrico tende a zero. Em outras palavras, há um limite de ação do campo elétrico, que está localizado em um ponto muito distante (tendendo ao infinito) do corpo. Esta ideia da Física nos remete a noção de fronteira na teoria bourdiana. As fronteiras de um determinado subespaço social dependem da estrutura das relações de disputa entre os agentes deste subespaço; elas podem se expandir ou contrair, se atenuar ou se fortalecer, sempre dependendo da 
distribuição de capital específico dos agentes dentro do subespaço (Bourdieu, 1983c).

O estudo da fronteira e da autonomia dos campos também foi tema de pesquisas na área da Educação em Ciências. Watanabe, Ribeiro e Kawamura (2013) investiram no estudo da interface entre divulgação científica/espaços não formais/educação científica. As autoras concluem, a partir da análise da produção sobre estes temas nas revistas da área da Educação em Ciências, que um novo campo autônomo estaria em formação, o campo da divulgação científica e espaços não formais. As próprias autoras reconhecem a necessidade de estudos mais aprofundados sobre a posição dos agentes neste campo, as disposições, tomadas de posição, os capitais e, em particular, o capital cultural. Refletindo contrariamente a tentativa de hibridização de aspectos religiosos com conteúdos científicos, Dorvillé (2010) defende a importância do fortalecimento das delimitações do campo científico. Para o autor, é de suma importância o estabelecimento de políticas que objetivem fortalecer as fronteiras do campo científico e do campo escolar, afastando das aulas de ciências da escola e da universidade as influências do campo religioso. Em nossa visão, a sugestão de Dorvillé (2010) transparece a ideia de que o processo de estabelecimento de fronteiras dos campos seria um processo racionalmente arquitetado, ou seja, que dependeria apenas da vontade de um grupo específico de agentes.

Sendo os campos um microcosmo do cosmo social, um universo particular separado e relativamente autônomo, estão sujeitos às solicitações externas e são atravessados pelas necessidades de outros campos, como o do poder, econômico e político, assim, as lutas internas de um campo dependem sempre da homologia que mantém com as lutas externas a ele (Bourdieu, 1996). Apesar de existirem homologias estruturais e funcionais entre todos os campos, aquilo que se passa no interior de um campo não é reflexo direto das demandas externas, mas uma expressão simbólica refratada pela lógica própria do campo (Bourdieu, 1983b).

Ribeiro (2008) apresenta um estudo histórico de constituição da educação em química e dos embates do ensino com a área de química, reconstrói historicamente a criação de um curso de licenciatura em química mostrando os debates entre o campo político, científico e educacional. Nesse embate o campo educacional ficaria fragilizado, desvalorizando as atividades de ensino, e essa seria uma condição estratégica para a hegemonia do campo científico nas lutas concorrenciais garantindo a sobrevivência e manutenção dos interesses específicos deste campo na constituição do curso em análise (Ribeiro, 2008). No trabalho de Condenanza e Cordero (2011) se discute a interface e homologia entre campos, para as autoras, a educação ambiental está impregnada de debates próprios de outros campos como o científico, o da educação e o da gestão ambiental e se instaura como um novo campo de interseç̧ão. As investigações e elaborações teóricas, que incidem nesse campo, emergiram de questionamentos de uma série de disciplinas vinculadas à educação ambiental como economia política e engenharia ambiental. O setor privado, assim como, organizações internacionais também incidem na definição do campo em termos de tendências, posturas e correntes educacionais. Sua autonomia provém do entrecruzamento desses diferentes campos e das determinações 
provenientes de cada um. De modo sucinto, para as autoras, a educação ambiental pode ser entendida como um campo emergente que envolve múltiplos discursos pedagógicos e práticas educativas centradas no ambiente e na natureza, e ainda com incipiente produção científica (Condenanza \& Cordero, 2011).

$\mathrm{Na}$ mesma linha de investigação da interface entre campos, a tese defendida por Watanabe (2015) tem como tema principal a divulgação científica produzida por cientistas. Em particular, trata das interações entre cientistas-divulgadores e alunos da educação básica. Para a autora, a divulgação científica é uma fronteira que se constitui do elo entre dois mundos, da interface entre o campo científico e o campo escolar. Nestes termos, a divulgação científica é o espaço de criação na fronteira e como atividade proveniente da fronteira, capaz de absorver, adaptar e refletir os discursos oriundos dos dois espaços. A partir desta noção chega-se ao entendimento de que a divulgação científica é o produto dos embates do campo científico com outros campos sociais. A interação entre agentes de campos distintos também foi investigada por Braga (2004) no seu trabalho de mestrado. A autora investe na análise das relações entre agentes/ atores envolvidos nas práticas de dois campos bem estabelecidos, o campo artístico e o campo científico. Para Braga (2004), na interseção entre Arte e Ciência define-se um subcampo, interno ao campo do Museu ou Centro de Ciências, com objetivos, lutas e disputas próprias dos agentes dos campos relacionados ao tema.

Como anteriormente discutido, as pesquisas de Freitas (2008), Freitas, Oliveira e Carvalho (2005) e Genovese (2013) há um enfoque em espaços “inter-campos” ou de intersecção entre campos, revelando a tentativa de preencher uma lacuna deixada por Bourdieu que não discute sobre as possíveis interações entre campos e a posição dos agentes nesse contexto em função dos valores distintos de seus capitais. Freitas (2008) identifica situações de proximidade entre os agentes, por exemplo no caso de uma professora oriunda de universidade com "capital simbólico válido no campo acadêmico" (p. 58); situações de reconhecimento das estruturas de poder; identificando o que estava em jogo nas disputas entre os agentes; analisando as situações de legitimidade e hierarquia, entendidas como reconhecimento e analisadas como "capital reconhecido no segmento escolar" e "capital reconhecido no segmento acadêmico" (p. 83); e avaliando, principalmente, a proximidade e a distância entre os agentes no campo. O texto apresenta diversos "caminhos" para aproximar o professor universitário e a escola, por exemplo, visando amenizar a hierarquia entre eles e aproveitando o espaço "inter-campos" que foi criado.

Outro conceito para entender a teoria dos campos é a luta entre antagonistas: o pretendente (dominado) que quer entrar forçando o direito de entrada e o nativo (dominante) que defende o monopólio e tenta excluir as concorrências (Bourdieu, 1989a). Como todo jogo, os agentes utilizam estratégias para modificar ou manter sua posição na estrutura do campo, visando posições mais favoráveis. As estratégias podem ser de conservação ou subversão, aqueles que detém mais capital específico tendem às estratégias de conservação (ortodoxia), enquanto aqueles que detém menos capital 
tendem às estratégias de subversão (heresia, heterodoxia) da estrutura e de suas posições (Bourdieu, 1983c). As estratégias decorrem da relação inconsciente entre o habitus e o campo (Bourdieu, 1989a).

Todas as pessoas engajadas no campo têm, em estado de doxa, interesses fundamentais em comum, ligados à axiomática fundamental do campo. Há um acordo, tacitamente aceito, entre aqueles que disputam o campo sobre o que merece ser disputado. Ao participar dessa luta se reproduz o jogo e se produz a crença de que ele existe e vale a pena ser jogado, a crença no jogo é o pedestal no qual repousa o jogo inteiro (Bourdieu, 1989a). Ao agente cabe jogá-lo sem recusá-lo, pois contestar as regras, recusar o nomos do jogo é pôr em jogo o próprio jogo e a crença que o funda, para Bourdieu (1996, p. 196) essa é a "única transgressão inexpiável”.

O que mantém essa estrutura unificada é a luta que se disputa, é o próprio jogo que está sendo jogado. O campo não é formado por um conjunto de agentes individuais ligados por simples interação ou cooperação. Trata-se, na verdade, de uma rede de relações objetivas entre posições que formam uma estrutura, um espaço de posições e tomadas de posições onde cada posição é objetivamente definida por sua relação com outras posições. Todas as posições dependem da situação atual e potencial na estrutura, dada pela distribuição desigual de capital (Bourdieu, 1996).

Nesse jogo há jogadas possíveis e outras impensáveis, as posições dos jogadores dependem das tomadas de posição dentre um espaço de possíveis. Orientadas pelas categorias de percepção do habitus, as tomadas de posições se anunciam como potencialidades objetivas, como coisas a fazer, movimentos a lançar, revistas a criar, adversários a combater, posições a superar etc. (Bourdieu, 1996). O campo é esse universo "onde existir é diferir, isto é, ocupar uma posição distinta e distintiva" (Bourdieu, 1996, p. 271). Além disso, as posições no campo são construídas segundo a estrutura do próprio campo, e são homólogas às posições que os agentes ocupam em outros campos, como o campo social e o do poder. Conforme discutido, quanto mais próximos dois corpos eletricamente carregados estiverem no espaço físico, maior a intensidade da força de interação entre eles. Em termos bourdianos, a atração entre dois agentes será maior quanto mais similares eles forem em relação aos aspectos sociais (Klüger, 2018). A partir desta ideia, entendemos que a distância entre agentes no espaço social e a distância entre partículas carregadas no espaço físico possuem significados muito semelhantes, uma vez que implicam em uma maior força de interação. Esta ideia pode ser corroborada a partir do próprio conceito de distância presente na Análise de Correspondência Múltipla (ACM), ferramenta estatística amplamente utilizada por Bourdieu nas suas pesquisas. Nesta técnica estatística, pontos são posicionados no espaço a partir de diferenças e similitudes indicadas por dados categóricos (Greenacre, 2017). Estes pontos podem ser agentes, instituições ou nações. No caso de posicionar agentes a partir de dados categóricos referentes a características sociais, a distância entre dois agentes indica uma maior homogeneidade de suas propriedades sociais (Klüger, 2018). Assim, quando dois indivíduos possuem a mesma propriedade social (ou marcam a mesma categoria em 
uma questão de certo survey), a distância entre eles é rigorosamente zero, indicando uma máxima "atração" possível. Da mesma forma, pela lei de Coulomb, notamos que se a distância tender a zero, a força de interação entre os agentes tenderá ao infinito. Pela capacidade de representar um espaço que, dependendo dos dados utilizados, pode ser entendido como uma representação do próprio espaço social, as ACM foram amplamente utilizadas por Bourdieu nas suas investigações (Klüger, 2018; Le Roux \& Rouanet, 2010). Este fato reforça nossa proposição de que a distância entre partículas carregadas eletricamente no espaço físico pode ser aproximada do conceito de distância entre agentes no espaço social.

Por fim, cada ato do jogo contém em si a história do jogo, todo seu passado e seus princípios. A história do campo marca a produção desse campo e a vida do produtor (jogador), é impossível compreender o produto de um campo e o seu valor sem conhecer a história do campo no qual ele foi produzido (Bourdieu, 1989a). A história do campo é retratada em diferentes trabalhos (Conceição, 2008; Condenanza 2012; Condenanza \& Cordero 2011; Feres, 2010; Ribeiro, 2008). Em geral, os autores apresentam uma espécie de sociogênese do campo, reconstruindo suas origens, identificando seus agentes, algumas disputas e interfaces com outros campos. Contudo, nessas pesquisas, geralmente, a análise histórica aparece como um capítulo introdutório, para situar o objeto, no qual são mobilizados alguns ou nenhum conceito da teoria dos campos e de forma mais descritiva e não relacional. A sociogênese histórica do campo é um dos procedimentos para análise de um campo (Bourdieu, 1996) e, por isso, entendemos que essa seria uma etapa fundamental em uma pesquisa que busca caracterizar um campo e não apenas como um tópico introdutório.

Além das leis invariáveis de cada campo, destacamos algumas propriedades específicas para ilustrar a mobilização desse conceito. No campo da alta costura, Bourdieu (2002a) destaca que a disputa entre dominantes e dominados costuma remeter ao velho e ao novo, tanto no estilo quanto no público consumidor do estilista, em que a inovação se choca com a tradição; além disso, nesse campo ocorre o fenômeno de transubstanciação em que um nome é transposto, na forma de marca, para um objeto ou um agente (discípulo de determinada maison) transferindo assim parte do seu capital simbólico. No campo jurídico, Bourdieu (1989c), destaca o papel da linguagem e da elitização na construção da autonomia relativa desse campo que, contraditoriamente, convive com uma forte dependência ou influência externa desse campo em relação a outros (poder, econômico, etc). No campo artístico, Bourdieu (1996) desenvolveu sua análise mais completa desse conceito destacando, principalmente, a sociogênese do campo e a relação entre produtor e consumidor na configuração das disputas e posições dos agentes. No campo econômico, Bourdieu (2005) destacou o papel das sanções brutais, associadas à maximização do lucro, que contrastam com as sanções simbólicas presentes na maioria dos outros campos. No campo intelectual, a originalidade ou genialidade do criador desponta como elemento importante na configuração desse campo (Bourdieu, 2004d). Além disso, tanto o campo intelectual quanto o científico (Bourdieu, 1983a, 2004a, 
2004b), evidenciam dois capitais específicos e concorrentes, sendo possível distinguir o capital científico institucional (temporal), próprio de trajetórias mais voltadas para ocupação de postos político-científicos, e o capital científico puro (específico), possuído por cientistas com elevado capital simbólico decorrente de sua produção de conhecimento científico.

Percebe-se a iniciativa dos pesquisadores em Educação em Ciências em criar novos campos para interpretar seus objetos de estudo. Feres (2010) propõe que o ensino de ciências é um campo científico representado pela pós-graduação. Condenanza (2012) reconhece a educação ambiental como um campo. Já Watanabe, Ribeiro e Kawamura (2013) estabelecem a compreensão da existência de um campo da divulgação científica/ espaços não formais na interface com a educação científica. Para as autoras, este campo seria um subcampo do campo da educação científica, concordando com a proposta de Feres (2010). Freitas e Fernandez (2015) criam o campo da docência no ensino superior e Genovese $(2008,2013)$ e Freitas (2008) partem da premissa, em suas pesquisas, de que existe um campo escolar ou um campo da escola. Como discutido anteriormente, entendemos que a delimitação do campo é um tema pouco claro no referencial bourdiano, mas defendemos o critério de reconhecimento e rentabilidade do capital específico não só no interior, mas também fora do campo como uma referência que dificulta o entendimento desses casos como campos.

Compreender o trabalho científico realizado por Bourdieu exige a aplicação prática de fazer funcionar um modo de pensamento. Esse importante sociólogo construiu um método praxiológico de análise fundado na empiria e em uma teoria científica. Para ele, "os trabalhos científicos são parecidos com uma música que fosse feita não para ser mais ou menos passivamente escutada, ou mesmo executada, mas sim para fornecer princípios de composição" (Bourdieu, 1989a, p. 63). O conceito de campo deve ser empregado assim, como uma apropriação ativa do modo de pensamento científico.

Nessa perspectiva, pensando em termos metodológicos, Bourdieu (1996) propõe que o estudo de qualquer campo deve operar por três procedimentos básicos e intrinsecamente ligados: i) a análise da posição do campo no seio do campo do poder e de sua evolução no decorrer do tempo; ii) a análise da estrutura interna do campo, isto é, da estrutura das relações objetivas entre as posições ocupadas pelos agentes ou grupos em concorrência; iii) a análise da gênese dos habitus dos ocupantes dessas posições. Em As regras da arte (1996) o sociólogo traça o processo de autonomização do campo literário por meio da sociogênese histórica desse campo, operando principalmente segundo os dois primeiros procedimentos destacados acima. O terceiro procedimento é aprofundado no Homo Academicus, no qual Bourdieu (2017) analisa o habitus e as posições ocupadas no campo universitário francês da década de 1960 fazendo uso do método prosopográfico e de análises estatísticas, como a ACM.

Quando nos voltamos para os trabalhos da Educação em Ciências, notamos que em alguns casos os autores apresentam as ideias bourdianas, mas não as mobilizam para pensar o objeto. Nos casos discutidos anteriormente, em que os autores parecem definir 
a existência do campo como um a priori, sentimos falta de um embasamento empírico maior, principalmente, pautado em dados quantitativos ou nas etapas de pesquisas sobre campo propostas por Bourdieu (1996): relação com o campo do poder, a prosopografia dos agentes e a sociogênese do campo. Por outro lado, reconhecemos que trata-se de um esforço analítico muito grande que provavelmente seria inviável, até mesmo para um doutorado, no contexto de produção de pesquisa que vivenciamos, que é completamente distinto do contexto francês.

Como destacado anteriormente, outra incoerência metodológica identificada na área remete à preocupação, legítima, de nossos colegas em resolver problemas da Educação em Ciências. Por um lado, essa é uma preocupação principal da nossa área, que justifica e legitima a intenção dos autores, por outro lado, a escolha pelo referencial bourdiano nos parece incompatível com essa demanda. Bourdieu é um autor que nos permite compreender a situação social de modo profundo, porém não permite produzir encaminhamentos pedagógicos, tanto por não ser um pedagogo quanto por não se preocupar em prescrever saídas para os cenários desanimadores que constrói. Isso fica claro em obras como $A$ miséria do mundo e $O$ desencantamento do mundo. Mesmo quando analisa o sistema de ensino, em A reprodução e Os herdeiros, seu foco é desvendar o papel da escola na reprodução das desigualdades sociais e não apontar caminhos de transformação dessa realidade. Apesar de defender um papel militante para o intelectual, nos momentos finais de sua produção e, principalmente, em textos não acadêmicos (Bourdieu, 2002b), essa prescrição não é diretiva no sentido de orientar ações de intervenção na sociedade, mas de defender uma compreensão social e divulgação desse entendimento. Além disso, a profundidade do diagnóstico produzido pelas análises bourdianas aponta para relações de poder entre classes sociais, cuja superação exigiria uma alteração social profunda que não compete às pesquisas em Educação em Ciências. Suas premissas teóricas consideram, principalmente, o aspecto inconsciente da incorporação das estruturas sociais pelos indivíduos, portanto, defender um processo de conscientização e mudança de habitus, embora seja desejável, se mostra muito pouco provável segundo a teoria de Bourdieu (1979). Por outro lado, os diversos exemplos de pesquisas da área trazidos neste artigo ilustram a potencialidade deste autor no sentido de avançar significativamente no entendimento dos problemas estudados pela área. Infelizmente, a mobilização de sua teoria não traz resultados otimistas, mas escancara o tamanho dos desafios que vivenciamos como pesquisadores em Educação em Ciências.

\section{Conclusões e implicações}

O objetivo central do presente trabalho foi tornar o conceito de campo mais claro teoricamente. Reconhecendo a multiplicidade de elementos que perpassam o conceito de campo (habitus, capital, estratégia, estrutura, entre outros), o que efetivamente dificulta a sua apropriação (Lahire, 2017; Montagner \& Montagner, 2010), nos envolvemos ao longo de um ano com a leitura das principais obras do autor que abordam esta temática. A leitura cuidadosa dos textos em articulação com longas discussões e elaborações de 
sínteses pelos autores, permitiu que construíssemos um entendimento profundo dessa teoria, para além da interpretação isolada dos conceitos, como habitus e capital. Este mergulho na teoria bourdiana nos fez perceber as inúmeras idiossincrasias que circulam o conceito de campo, o que motivou a elaboração deste texto, a fim de contribuir com a área da Educação em Ciências. Em paralelo, associamos à nossa interpretação da teoria dos campos alguns conceitos da Física, em particular do eletromagnetismo, com a intenção de facilitar a interpretação de certos aspectos. Ademais, nos voltamos para um conjunto de trabalhos da área de Educação em Ciências que mobilizaram o conceito nas suas pesquisas (Valadão, 2016), a fim de avançar no entendimento teórico em diálogo com a área e ilustrar as articulações possíveis e as efetivadas.

Partimos da relação entre o conceito de campo, de espaço social e de espaço físico. Mostramos que o espaço social, estudado por Bourdieu, se apoia no entendimento contemporâneo de espaço físico, no qual as dimensões espaciais estão imbricadas com a dimensão temporal. Avançamos para a apresentação das leis gerais e invariáveis dos campos e concluímos com o detalhamento das suas propriedades específicas, sempre dialogando, quando possível, com aspectos da Física e com os trabalhos da área da Educação em Ciências.

Bourdieu entende que os campos são subespaços estruturados do espaço social. A sua estrutura provém das disputas entre agentes (ou instituições) por bens simbólicos e/ou materiais, somente percebidos como objeto de interesse por quem faz parte do campo ou por quem almeja nele ingressar. Isso tem como consequência o fato de que não é qualquer profissão ou área do conhecimento que pode ser considerado um campo autônomo. Existem leis gerais e invariáveis, assim como propriedades específicas dos campos que nos ajudam a entender melhor esses espaços. Discutimos a necessidade de se investir no reconhecimento dos objetos que estão em disputa e dos interesses dos agentes que fazem parte ou que pretendem fazer parte do campo. Percebemos que, em geral, nos trabalhos da área da Educação em Ciências os campos analisados são adequadamente definidos apenas como "espaços estruturados de posições". Porém, os pesquisadores não investem no mapeamento do fator responsável pela estruturação das posições no espaço social, o volume de capital específico em posse dos, e em disputa pelos, agentes. Ademais, percebemos que o capital específico precisa ser reconhecido fora das fronteiras do campo. Ressaltamos que o entendimento do que é ou não um campo não é claro na obra bourdiana e notamos que alguns espaços são interpretados ora como campo ora como subcampo, dependendo das relações que estão sendo analisadas. Além disso, nossa leitura das obras nos permite considerar que todos estamos inseridos no campo linguístico e no campo das classes sociais, disputando capitais mais rentáveis e posições mais legítimas nesses campos. Assim, é necessário fazer a diferenciação das disputas próprias de um campo específico daquelas gerais de classes sociais, por exemplo.

Seguimos as análises discutindo as características das pessoas ou instituições que podem ser consideradas como agentes do campo. Esses agentes são dotados de um habitus próprio que implica em conhecer e reconhecer as leis desse campo e define as 
posições que poderão ocupar (Bourdieu, 1989a). A Física clássica nos ajuda a entender essa ideia uma vez que, no campo eletrostático, por exemplo, são as próprias partículas carregadas as responsáveis pela geração do campo no qual elas estão inseridas e sua interação com outras partículas carregadas configura o próprio campo. Neste senso, não deve-se considerar qualquer pessoa como agente do campo em análise, assim como partículas neutras não contribuem para a configuração do campo eletrostático. Na área da Educação em Ciências, notamos que alguns trabalhos relativizam muito o critério de entrada no campo, contrariando, na nossa interpretação, o rigor da teoria bourdiana ao estipular quem está dentro e quem está fora no campo.

A interpretação de que a força de um agente e sua posição no campo dependem do seu patrimônio de capitais é outro elemento chave na teoria bourdiana. Na Física clássica observamos fenômeno semelhante no estudo da eletrostática. É uma propriedade intrínseca das partículas, a carga elétrica, que define o quanto esta partícula será capaz de atrair (ou repelir) outra. Em analogia com o espaço social, quanto mais frequente for uma propriedade social de um agente na comparação com outros agentes do campo, maior a sua capacidade agregadora, ou seja, maior a sua força no interior deste espaço. Nos trabalhos da área da Educação em Ciências, identificamos um conjunto de autores que investiram na definição de um capital específico para o campo e suas implicações nas posições dos agentes (Condenanza, 2012; Freitas \& Fernandez, 2015; Genovese, 2008; Perrelli \& Gianotto, 2005; Ribeiro, 2008).

Sobre limites e fronteiras dos campos, que são também objeto de conflito e disputa no interior do campo, reforçamos que defender as fronteiras é defender a disputa estabelecida no campo, seu nomos e suas regras. Mostramos que, na Física, o estudo do campo elétrico revela que sua intensidade diminui com a distância, logo, quando a distância tende ao infinito, a intensidade do campo elétrico tende a zero. Quer dizer, assim como na eletrostática, há na teoria bourdiana um limite para atuação do campo, suas fronteiras, que dependem da estrutura das relações de disputa entre os agentes deste subespaço. $\mathrm{O}$ tema da fronteira e da autonomia dos campos também foi objeto de pesquisa na área da Educação em Ciências (Condenanza \& Cordero, 2011; Dorvillé, 2010; Watanabe, 2015; Watanabe et al., 2013).

Sobre a questão metodológica, Bourdieu nos mostra que o estudo de qualquer campo precisa operar a partir de três procedimentos organicamente relacionados: analisar a posição do campo no seio do campo do poder; olhar para a estrutura das relações objetivas entre as posições ocupadas pelos agente e analisar a gênese dos habitus dos ocupantes dessas posições.

Em síntese, sobre o conjunto de trabalhos da área da Educação em Ciências que ilustramos para avançar no entendimento deste complexo conceito, que é o de campo, percebemos que há uma definição, em geral, apriorística dos campos, sem o investimento em estudos empíricos que corroboram as considerações prévias. Identificamos também que os pesquisadores da área utilizam o referencial bourdiano para resolver problemas da Educação em Ciências. Sabemos que é uma preocupação legítima dos autores, porém, 
esta escolha nos parece incompatível com essa demanda, pois Bourdieu é um autor que ajuda a compreender de modo profundo uma situação social estática, mas sua teoria não permite interpretar soluções que transformem estas realidades, principalmente se não forem mudanças estruturais na sociedade. Reconhecemos, contudo, que uma apropriação ativa do modo de pensamento científico de Bourdieu, que contemple suas proposições teóricas e recomendações metodológicas, demanda um esforço analítico muito grande, dificilmente contemplado em pesquisas usualmente realizadas na área, até mesmo de doutorado.

Apesar desses desafios de entendimento, reconhecidos pelo próprio autor (Bourdieu, 2013), insistimos na potencialidade deste referencial em contribuir com as pesquisas em Educação em Ciências. Os diversos estudos citados neste artigo ilustram a variedade de objetos caros à nossa área que podem ser interpretados pela lente bourdiana, como a escola, a universidade, os espaços não formais e a ciência em geral. Além disso, sua Sociologia da Ciência e seu pensamento relacional permitem superar a dicotomia internalista e externalista e articular efetivamente o indivíduo ou grupo ao contexto social; bem como, ao fornecer uma imagem precisa sobre as relações de poder envolvidas nos campos e subcampos científicos, permite colocar a ciência a serviço de seu próprio progresso orientando a tomada de posições prescritivas que podem nos orientar frente à decisões importantes diante de órgão de regulação e fomento.

\section{Agradecimentos}

O presente trabalho foi realizado com apoio da Coordenação de Aperfeiçoamento de Pessoal de Nível Superior - Brasil (CAPES) - Código de Financiamento 001.

\section{Referências}

Bourdieu, P. (1968). Campo intelectual e projeto criador. In J. Pouillon (Org.), Problemas do estruturalismo (pp. 105-145). Zahar.

Bourdieu, P. (1979). O desencantamento do mundo: estruturas econômicas e estruturas temporais. Editora Perspectiva.

Bourdieu, P. (1983a). O campo científico. In R. Ortiz (Org.), Pierre Bourdieu: Sociologia, (pp. 122-155). Ed. Ática.

Bourdieu, P. (1983b). Mas quem criou os criadores? In P. Bourdieu, Questões de sociologia (pp. 162-172). Ed. Marco Zero.

Bourdieu, P. (1983c). Algumas propriedades dos campos. In P. Bourdieu, Questões de Sociologia (pp. 89-94). Ed. Marco Zero.

Bourdieu, P. (1989a). A gênese dos conceitos de habitus e de campo. In P. Bourdieu, $O$ poder simbólico (pp. 59-73). Ed. Difel/Bertrand. 
Bourdieu, P. (1989b). A representação política. Elementos para uma teoria do campo político. In P. Bourdieu, O poder simbólico (pp. 163-207). Ed. Difel/Bertrand.

Bourdieu, P. (1989c). A força do direito. Elementos para uma sociologia do campo jurídico. In P. Bourdieu, O poder simbólico (pp. 209-254). Ed. Difel/Bertrand.

Bourdieu, P. (1996). As regras da arte: gênese e estrutura do campo literário. Companhia das Letras.

Bourdieu, P. (2002a). O costureiro e sua grife: uma contribuição para a teoria da magia. In P. Bourdieu, A Produção da crença: contribuição para uma teoria dos bens simbólicos (pp. 113-190). Ed. Zouk.

Bourdieu, P. (2002b). Pour un savoir engagé. Le monde diplomatique. https://www. monde-diplomatique.fr/2002/02/BOURDIEU/8602

Bourdieu, P. (2004a). Os usos sociais da ciência: por uma sociologia clínica do campo científico. Editora UNESP.

Bourdieu, P. (2004b). Para uma sociologia da ciência. Edições 70.

Bourdieu, P. (2004c). Programa para uma sociologia do esporte. In P. Bourdieu, Coisas Ditas (pp. 207-220). Ed. Brasiliense.

Bourdieu, P. (2004d). O campo intelectual: um mundo à parte. In P. Bourdieu, Coisas Ditas (pp. 169-180). Ed. Brasiliense.

Bourdieu, P. (2005). O campo econômico. Política e sociedade, 4(6).

Bourdieu, P. (2007a). Gênese e estrutura do campo religioso. In P. Bourdieu, A economia das trocas simbólicas (pp. 27-78). Ed. Perspectiva.

Bourdieu, P. (2007b). A distinção: crítica social do julgamento. Zouk.

Bourdieu, P. (2008). A economia das trocas linguísticas: o que falar quer dizer. 2.ed. EDUSP.

Bourdieu, P. (2013). Sèminaires sur le concept de champ, 1972-1975. Actes de la recherche en Sciences Sociales, 200, 4-37.

Bourdieu, P. (2017). Homo academicus. 2 ed. Editora da UFSC.

Braga, M. do R. A. (2004). Relações entre Arte e Ciência em Centros e Museus de Ciências. (Dissertação de mestrado em História das Ciências da Saúde). Casa de Oswaldo Cruz FIOCRUZ, Rio de Janeiro.

Conceição, A. J. (2012). Contribuições do programa de iniciação científica júnior na Universidade Estadual de Londrina (UEL): a formação de um habitus adequado ao campo científico. (Dissertação de Mestrado em Políticas Públicas). Universidade Estadual de Maringá, Maringá. 
Condenanza, L. M. (2012). Ley Federal de Educación e Ley de Educación Nacional: Un análisis desde la Educación Ambiental. (Tese Licenciatura em Ciências da educação). Universidad Nacional de La Plata, Facultad de Humanidades y Ciencias de la Educación, Departamento de Ciencias de la Educación, La Plata, Argentina.

Condenanza, L., \& Cordero, S. (2011). La educación ambiental desde la teoria de los campos. In Encontro Nacional de Pesquisa em Educação em Ciências. Campinas, SP.

Dorvillé, L. F. M. (2010). Religião, escola e ciência: conflitos e tensões nas visões de mundo de alunos de uma licenciatura em ciências biológicas. (Tese de doutorado em Educação). Faculdade de Educação, Universidade Federal Fluminense, Rio de Janeiro.

dos Reis, U. V., \& Reis, J. C. (2016). Os conceitos de espaço e de tempo como protagonistas no ensino de Física: um relato sobre uma sequência didática com abordagem históricofilosófica. Caderno Brasileiro de Ensino de Física, 33(3), 744-778.

Einstein, A. (2011). The world as I see it. Open Road Media.

Feres, G. G. (2010). A pós-graduação em Ensino de Ciências no Brasil: uma leitura a partir da Teoria de Bourdieu. (Tese de Doutorado em Educação para a Ciência). Faculdade de Ciências, Universidade Estadual Paulista, Bauru.

Feres, G. G., \& Nardi, R. (2007). Parâmetros utilizados para caracterização e avaliação da produção acadêmica na área de Educação em Ciências: estudos preliminares. In Encontro Nacional de Pesquisa em Educação em Ciências. Florianópolis, SC.

Fogle, N. (2011). The spatial logic of social struggle: a bourdieuian topology. Lexington Books..

Freitas, Z. L. (2008). Um Projeto de Interação Universidade-Escola como Espaço Formativo para a Docência do Professor Universitário. (Doutorado em Educação para a Ciência). Faculdade de Ciências, Universidade Estadual Paulista, Bauru.

Freire, L. I. F., \& Fernandez, C. (2015). O professor universitário novato: tensões, dilemas e aprendizados no início da carreira docente. Ciência \& Educação, 21(1), 255-272.

Freitas, Z. L., Oliveira, E. R., \& Carvalho, L. M. O. (2005). Formação contínua de professores da universidade: pesquisadores em Ciências. In Encontro Nacional de Pesquisa em Educação em Ciências. Bauru, SP.

Gentner, D. (1983). Structure-mapping: A theoretical framework for analogy. Cognitive science, 7(2), 155-170.

Genovez, L. G. R. (2008). Homo Magister: conhecimento e reconhecimento de uma professora de ciências pelo campo escolar. (Tese de doutorado em Educação para a Ciência). Faculdade de Ciências, Universidade Estadual Paulista, Bauru.

Genovese, L. G. R. (2013). Obstáculos à Consolidação da Relação entre o Campo Escolar e o Campo Universitário: os Pequenos Grupos de Pesquisa de Goiás em foco. In Encontro Nacional de Pesquisa em Educação em Ciências. Águas de Lindóia, SP. 
Greenacre, M. (2017). Correspondence analysis in practice. CRC press.

Grenfell, M. (2018). Uma reflexão sobre a teoria do campo (e dentro dela) na prática. Tempo Social, revista de sociologia da USP, 30(2).

Griffiths, D. J. (2005). Introduction to electrodynamics. Pearson.

Jackson, J. D. (2007). Classical electrodynamics. John Wiley \& Sons.

Jammer, M. (1993). Concepts of space: the history of theories of space in physics (3a ed.). Dover Publications, 1993.

Klüger, E. (2018). Análise de correspondências múltiplas: fundamentos, elaboração e interpretação. Revista Brasileira de Informação Bibliográfica em Ciências Sociais, 86(2), 68-97. https://doi.org/10.17666/bib8604/2018

Lahire, B. (2002). Reprodução ou prolongamentos críticos? Educação \& Sociedade, ano XXIII, 78, abril, 37-55.

Lahire, B. (2017). Campo. In A. Catani et al. (Orgs.), Vocabulário Bourdieu (pp. 64-66). 1 ed. Autêntica Editora, 2017.

Le Roux, B., \& Rouanet, H. (2010). Multiple correspondence analysis. Sage, 163.

Martins, I., Gouveia, G., Jansen, M., Terreri, L., Fernandes, A., \& Assumpção, A. (2005). Textos, sujeitos e discursos: apropriação de textos de Ciências por formadores de professores. In Encontro Nacional de Pesquisa em Educação em Ciências. Bauru, SP.

Montagner, M. A., \& Montagner, M. I. (2010). A teoria geral dos campos de Pierre Bourdieu: uma leitura. Revista Tempus Actas de Saúde Coletiva, 5(2), 255-273.

Mozzer, N. B., \& Justi, R. (2013). A elaboração de analogias como um processo que favorece a expressão de concepções de professores de química. Educación Química, 24, 163-173.

Nussenzveig, H. M. (2015). Curso de física básica: Eletromagnetismo. Editora Blucher, 3.

Pereira, J. E. D. (1999). Aspectos sócio-históricos da formação inicial de professores de Biologia. In Encontro Nacional de Pesquisa em Educação em Ciências. Valinhos, SP.

Perrelli, M. A. S. (1996). Transposição didática no campo da indústria cultural: um estudo dos condicionantes dos conteúdos de Ciências nos livros didáticos. (Dissertação de mestrado em Ciências da Educação). Programa de Pós Graduação em Educação, Universidade Federal de Santa Catarina, Florianópolis.

Perrelli, M. A. S., \& Gianotto, D. E. P. Percepções de professores universitários sobre a iniciação científica: uma análise a partir de Pierre Bourdieu e Thomas Kuhn. In Encontro Nacional de Pesquisa em Educação em Ciências. Bauru, SP.

Porto, C. M., \& Porto, M. M. (2008). Uma visão do espaço na mecânica newtoniana e na teoria da relatividade de Einstein. Revista Brasileira de Ensino de Física, 30(1), 1603.11603.8. https://doi.org/10.1590/S1806-11172008000100017 
Ribeiro, L. C. S. (2008). A criação da licenciatura noturna em química da UFRJ: embates, retóricas e conciliações. (Tese de doutorado em Educação: História, Política e Sociedade). Pontifícia Universidade Católica de São Paulo, São Paulo.

Valadão, L. D. (2016). Apropriação da perspectiva teórica de Bourdieu na pesquisa em Educação em Ciências: uma revisão bibliográfica. (Dissertação de mestrado em Educação). Faculdade de Educação, Universidade Federal de Juiz de Fora, Juiz de Fora.

Watanabe, G. (2015). A divulgação científica produzida por cientista: contribuições para o capital cultural. (Tese de doutorado em Ensino de Física). Faculdade de Educação, Instituto de Física, Instituto de Química e Instituto de Biociências, Universidade de São Paulo, São Paulo.

Watanabe, G., Ribeiro, R. A., \& Kawamura, M. R. D. (2013). A pesquisa em divulgação científica e espaços não formais de educação como campo. In Encontro Nacional de Pesquisa em Educação em Ciências. Águas de Lindóia, SP. 
${ }^{\circledR}$ Luciana Massi

Universidade Estadual Paulista (UNESP)

Faculdade de Ciências e Letras

Departamento de Educação

Araraquara, São Paulo, Brasil

luciana.massi@unesp.br

Gabriela Agostini

Universidade Estadual Paulista (UNESP)

Faculdade de Ciências

Programa de pós-graduação em Educação para a Ciência Bauru, São Paulo, Brasil gabriela.agostini@unesp.br

${ }^{-1}$ Matheus Monteiro Nascimento

Universidade Federal do Rio Grande do Sul (UFRGS)

Instituto de Física, Departamento de Física

Porto Alegre, Rio Grande do Sul, Brasil

matheus.monteiro@ufrgs.br

Editor Responsável

Alessandro Damásio Trani Gomes

Manifestação de Atenção às Boas Práticas Científicas e de Isenção de Interesse

Os autores declaram ter cuidado de aspectos éticos ao longo do desenvolvimento da pesquisa e não ter qualquer interesse concorrente ou relações pessoais que possam ter influenciado o trabalho relatado no texto. 